\title{
Association of Weekend Admission and Weekend Discharge with Length of Stay and 30-Day Readmission in Children's Hospitals
}

\author{
Jessica L Markham, MD, MSc ${ }^{1 *}$; Troy Richardson, PhD ${ }^{1,2}$; Matthew Hall, PhD ${ }^{1,2}$; Christopher P Bonafide, MD, MSCE; \\ Derek J Williams, MD, MPH ${ }^{4}$; Katherine A. Auger, MD, MSc ${ }^{5,6}$; Karen M Wilson, MD, MPH'; Samir S Shah, MD, MSCE 5 ,6; \\ on behalf of the Pediatric Research in Inpatient Settings (PRIS) Network.
}

${ }^{1}$ Children's Mercy Kansas City, Kansas City, Missouri; ${ }^{2}$ Children's Hospital Association, Lenexa, Kansas; ${ }^{3}$ Children's Hospital of Philadelphia, Philadelphia, Pennsylvania; ${ }^{4}$ Vanderbilt University School of Medicine, Nashville, Tennessee; ${ }^{5}$ Cincinnati Children's Hospital Medical Center, Cincinnati, Ohio; ${ }^{6}$ University of Cincinnati School of Medicine, Cincinnati, Ohio; ${ }^{7}$ The Icahn School of Medicine at Mount Sinai, New York, New York.

BACKGROUND: Worse outcomes among adults presenting for/receiving care on weekends (ie, "the weekend effect") have been observed for many diseases. However, little is known about the overall impact of the weekend effect in hospitalized children.

OBJECTIVE: To determine the association between weekend admission and length of stay (LOS) and between weekend discharge and 30-day all-cause readmission.

METHODS: We conducted a retrospective, cross-sectional study of children hospitalized between October 1, 2014 and September 30, 2015 using the Pediatric Health Information System. Birth hospitalizations and planned procedures were excluded. We used generalized linear mixed modeling to assess the independent association between weekend admission and LOS and weekend discharge and readmission risk.

RESULTS: Among 390,745 hospitalizations across 43 hospitals, the median LOS was 41 hours (interquartile range
[IQR] 24-71) and the 30-day readmission rate was $8.2 \%$ (IQR 7.2-9.4). We observed no association between weekend admission and LOS (adjusted LOS [95\% Cl] weekend 63.70 [61.01-66.52] hours vs weekday 63.40 [60.73-66.19] hours, $P=.112$ ). Weekend discharge was associated with slightly increased odds of readmission compared with weekday discharge (adjusted probability of readmission [ $95 \% \mathrm{Cl}$ ]: weekend $0.13[0.12-0.13]$ vs weekday $0.11[0.11-0.12] ; P<$ .001) but was variable among individual hospitals. Patient characteristics (ie, number of chronic conditions) were more strongly associated with LOS and readmission risk than weekend admission or discharge.

CONCLUSIONS: Patient-level factors (ie, clinical and demographic characteristics) are more indicative of longer LOS and readmission risk than weekend admissions or discharges. The overall impact of the weekend effect across children's hospitals was minimal. Journal of Hospital Medicine 2019;14:75-82. @ 2019 Society of Hospital Medicine ncreasingly, metrics such as length of stay (LOS) and readmissions are being utilized in the United States to assess quality of healthcare because these factors may represent opportunities to reduce cost and improve healthcare delivery. ${ }^{1-8}$ However, the relatively low rate of pediatric readmissions, ${ }^{9}$ coupled with limited data regarding recommended LOS or best practices to prevent readmissions in children, challenges the ability of hospitals to safely reduce LOS and readmission rates for children. ${ }^{10-12}$

In adults, weekend admission is associated with prolonged LOS, increased readmission rates, and increased risk of mortality. ${ }^{13-21}$ This association is referred to as the "weekend effect." While the weekend effect has been examined in chil-

*Corresponding Author: Jessica L. Markham, MD, MSc; E-mail: jlmarkham@ cmh.edu; Telephone: 816-302-1493, Twitter: @jmarks614

Additional Supporting Information may be found in the online version of this article.

Received: March 25, 2018; Revised: July 12, 2018; Accepted: August 11, 2018 () 2019 Society of Hospital Medicine DOI 10.12788/jhm.3085 dren, the results of these studies have been variable, with some studies supporting this association and others refuting it. ${ }^{22-31}$ In contrast to patient demographic and clinical characteristics that are known to affect LOS and readmissions, ${ }^{32}$ the weekend effect represents a potentially modifiable aspect of a hospitalization that could be targeted to improve healthcare delivery.

With increasing national attention toward improving quality of care and reducing LOS and healthcare costs, more definitive evidence of the weekend effect is necessary to prioritize resource use at both the local and national levels. Therefore, we sought to determine the association of weekend admission and weekend discharge on LOS and 30-day readmissions, respectively, among a national cohort of children. We hypothesized that children admitted on the weekend would have longer LOS, whereas those discharged on the weekend would have higher readmission rates.

\section{METHODS}

Study Design and Data Source

We conducted a multicenter, retrospective, cross-sectional 
study. Data were obtained from the Pediatric Health Information System (PHIS), an administrative and billing database of 46 free-standing tertiary care pediatric hospitals affiliated with the Children's Hospital Association (Lenexa, Kansas). Patient data are de-identified within PHIS; however, encrypted patient identifiers allow individual patients to be followed across visits. This study was not considered human subjects research by the policies of the Cincinnati Children's Hospital Institutional Review Board.

\section{Participants}

We included hospitalizations to a PHIS-participating hospital for children aged 0-17 years between October 1, 2014 and September 30, 2015. We excluded children who were transferred from/to another institution, left against medical advice, or died in the hospital because these indications may result in incomplete LOS information and would not consistently contribute to readmission rates. We also excluded birth hospitalizations and children admitted for planned procedures. Birth hospitalizations were defined as hospitalizations that began on the day of birth. Planned procedures were identified using methodology previously described by Berry et al. ${ }^{9}$ With the use of this methodology, a planned procedure was identified if the coded primary procedure was one in which $>80 \%$ of cases (eg, spinal fusion) are scheduled in advance. Finally, we excluded data from three hospitals due to incomplete data (eg, no admission or discharge time recorded).

\section{Main Exposures}

No standard definition of weekend admission or discharge was identified in the literature..$^{33}$ Thus, we defined a weekend admission as an admission between 3:00 PM Friday and 2:59 PM Sunday and a weekend discharge as a discharge between 3:00 PM Friday and 11:59 PM Sunday. These times were chosen by group consensus to account for the potential differences in hospital care during weekend hours (eg, decreased levels of provider staffing, access to ancillary services). To allow for a full 30-day readmission window, we defined an index admission as a hospitalization with no admission within the preceding 30 days. Individual children may contribute more than one index hospitalization to the dataset.

\section{Main Outcomes}

Our outcomes included LOS for weekend admission and 30-day readmissions for weekend discharge. LOS, measured in hours, was defined using the reported admission and discharge times. Readmissions were defined as a return to the same hospital within the subsequent 30 days following discharge.

\section{Patient Demographics and Other Study Variables}

Patient demographics included age, gender, race/ethnicity, payer, and median household income quartile based on the patient's home ZIP code. Other study variables included presence of a complex chronic condition (CCC), ${ }^{34}$ technology dependence, ${ }^{34}$ number of chronic conditions of any complexity, admission through the emergency department, intensive care unit (ICU) admission, and case mix index. ICU admission and case mix index were chosen as markers for severity of illness. ICU admission was defined as any child who incurred ICU charges at any time following admission. Case mix index in $\mathrm{PHIS}$ is a relative weight assigned to each discharge based on the All-Patient Refined Diagnostic Group (APR-DRG; 3M) assignment and APR-DRG severity of illness, which ranges from 1 (minor) to 4 (extreme). The weights are derived by the Children's Hospital Association from the HCUP KID 2012 database as the ratio of the average cost for discharges within a specific APR-DRG severity of illness combination to the average cost for all discharges in the database.

\section{Statistical Analysis}

Continuous variables were summarized with medians and interquartile ranges, while categorical variables were summarized with frequencies and percentages. Differences in admission and discharge characteristics between weekend and weekday were assessed using Wilcoxon rank sum tests for continuous variables and chi-square tests of association for categorical variables. We used generalized linear mixed modeling (GLMM) techniques to assess the impact of weekend admission on LOS and weekend discharge on readmission, adjusting for important patient demographic and clinical characteristics. Furthermore, we used GLMM point estimates to describe the variation across hospitals of the impact of weekday versus weekend care on LOS and readmissions. We assumed an underlying log-normal distribution for LOS and an underlying binomial distribution for 30-day readmission. All GLMMs included a random intercept for each hospital to account for patient clustering within a hospital. All statistical analyses were performed using SAS v.9.4 (SAS Institute, Cary, North Carolina), and $P$ values $<.05$ were considered statistically significant.

\section{RESULTS}

We identified 390,745 hospitalizations that met inclusion criteria (Supplementary Figure 1). The median LOS among our cohort was 41 hours (interquartile range [IQR] 24-71) and the median 30-day readmission rate was 8.2\% (IQR 7.2-9.4).

\section{Admission Demographics for Weekends and Weekdays}

Among the included hospitalizations, 92,266 (23.6\%) admissions occurred on a weekend (Supplementary Table 1). Overall, a higher percentage of children $<5$ years of age were admitted on a weekend compared with those admitted on a weekday (53.3\% vs $49.1 \%, P<.001)$. We observed a small but statistically significant difference in the proportion of weekend versus weekday admissions according to gender, race/ethnicity, payer, and median household income quartile. Children with medical complexity and those with technology dependence were admitted less frequently on a weekend. A higher proportion of children were admitted through the emergency department on a weekend and a higher frequency of ICU utilization was observed for children admitted on a weekend compared with those admitted on a weekday. 


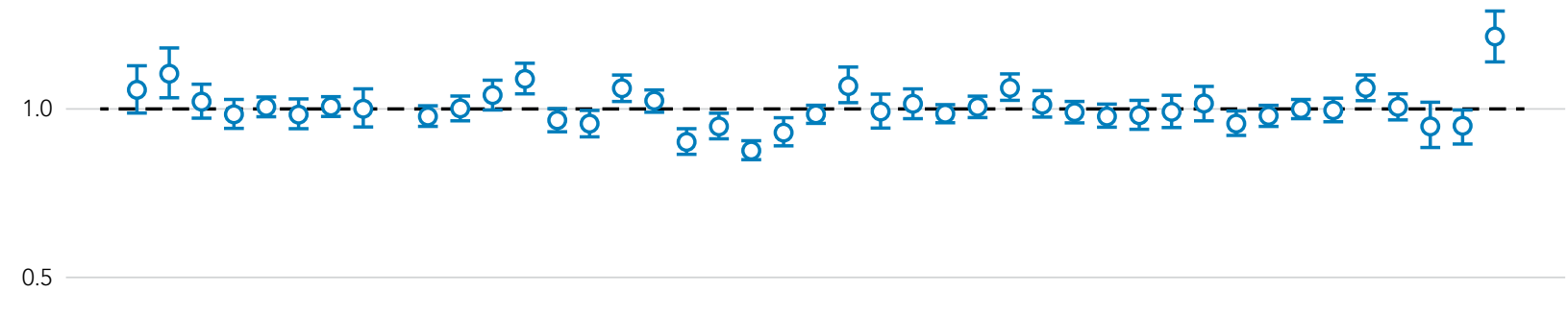

0.0

\section{PHIS Hospital}

FIG 1. Comparison of adjusted length of stay (LOS) for weekend versus weekday admissions across 43 Pediatric Health Information System (PHIS) hospitals. Data are presented as adjusted ratios of means with $95 \% \mathrm{Cl}$. Values $>1.0$ are observed for hospitals where weekend admissions were associated with longer length of stay (LOS), while values $<1.0$ are observed for hospitals where weekend admissions were associated with shorter LOS.

\section{Association Between Study Variables and Length of Stay}

In comparing adjusted LOS for weekend versus weekday admissions across 43 hospitals, not only did LOS vary across hospitals $(P<.001)$, but the association between LOS and weekend versus weekday care also varied across hospitals $(P<.001)$ (Figure 1). Weekend admission was associated with a significantly longer LOS at eight (18.6\%) hospitals and a significantly shorter LOS at four (9.3\%) hospitals with nonstatistically significant differences at the remaining hospitals.

In adjusted analyses, we observed that infants $\leq 30$ days of age, on average, had an adjusted LOS that was $24 \%$ longer than that of 15- to 17-year-olds, while children aged 1-14 years had an adjusted LOS that was 6\%-18\% shorter (Table 1). ICU utilization, admission through the emergency department, and number of chronic conditions had the greatest association with LOS. As the number of chronic conditions increased, the LOS increased. No association was found between weekend versus weekday admission and LOS (adjusted LOS [95\% Cl]: weekend 63.70 [61.01-66.52] hours versus weekday 63.40 [60.73-66.19] hours, $P=.112$ ).

\section{Discharge Demographics for Weekends} and Weekdays

Of the included hospitalizations, 127,421 (32.6\%) discharges occurred on a weekend (Supplementary Table 2). Overall, a greater percentage of weekend discharges comprised children $<5$ years of age compared with the percentage of weekday discharges for children $<5$ years of age $(51.5 \%$ vs $49.5 \%$, $P<.001)$. No statistically significant differences were found in gender, payer, or median household income quartile between those children discharged on a weekend versus those discharged on a weekday. We found small, statistically significant differences in the proportion of weekend versus weekday discharges according to race/ethnicity, with fewer non-Hispanic white children being discharged on the weekend versus weekday. Children with medical complexity, technology dependence, and patients with ICU utilization were less frequently discharged on a weekend compared with those discharged on a weekday.

\section{Association between Study Variables and Readmissions}

In comparing the adjusted odds of readmissions for weekend versus weekday discharges across 43 PHIS hospitals, we observed significant variation $(P<.001)$ in readmission rates from hospital to hospital (Figure 2). However, the direction of impact of weekend care on readmissions was similar $(P=.314)$ across hospitals (ie, for 37 of 43 hospitals, the readmission rate was greater for weekend discharges compared with that for weekday discharges). For 17 (39.5\%) of 43 hospitals, weekend discharge was associated with a significantly higher readmission rate, while the differences between weekday and weekend discharge were not statistically significant for the remaining hospitals.

In adjusted analyses, we observed that infants $<1$ year were more likely to be readmitted compared with 15- to 17-yearolds, while children 5-14 years of age were less likely to be readmitted (Table 2). Medical complexity and the number of chronic conditions had the greatest association with readmissions, with increased likelihood of readmission observed as the number of chronic conditions increased. Weekend discharge 
TABLE 1. Association between Patient Demographic and Clinical Characteristics and Length of Stay

\begin{tabular}{|c|c|c|c|}
\hline & $\begin{array}{l}\text { Ratio of Means } \\
\quad(95 \% \mathrm{Cl})\end{array}$ & $\begin{array}{c}\text { Adjusted LOS in Hours } \\
\qquad(95 \% \mathrm{Cl})\end{array}$ & $P$ Value \\
\hline \multicolumn{4}{|l|}{ Day of Admission } \\
\hline Weekday & Reference & $63.40(60.73,66.19)$ & \\
\hline \multicolumn{4}{|l|}{ Age Group } \\
\hline $0-30$ days & $1.24(1.23,1.26)$ & $81.91(78.35,85.62)$ & $<.001$ \\
\hline $1-4$ years & $0.82(0.81,0.82)$ & $53.83(51.56,56.21)$ & $<.001$ \\
\hline $5-9$ years & $0.84(0.83,0.85)$ & $55.21(52.87,57.65)$ & $<.001$ \\
\hline $10-14$ years & $0.94(0.93,0.94)$ & $61.62(59.01,64.36)$ & $<.001$ \\
\hline $15-17$ years & Reference & $65.90(63.09,68.84)$ & \\
\hline \multicolumn{4}{|l|}{ Gender } \\
\hline Female & $1.05(1.04,1.05)$ & $65.10(62.35,67.97)$ & $<.001$ \\
\hline Non-Hispanic Black & $1.00(1.00,1.01)$ & $61.63(59.07,64.31)$ & .345 \\
\hline Hispanic & $1.02(1.01,1.03)$ & $62.50(59.90,65.21)$ & $<.001$ \\
\hline Asian & $1.02(1.01,1.04)$ & $62.75(60.01,65.61)$ & .008 \\
\hline Native American & $1.14(1.08,1.20)$ & $69.73(65.21,74.56)$ & $<.001$ \\
\hline Other & $1.04(1.03,1.05)$ & $63.66(60.98,66.46)$ & $<.001$ \\
\hline \multicolumn{4}{|l|}{ Payer } \\
\hline Government & $1.04(1.03,1.05)$ & $64.83(62.13,67.66)$ & $<.0001$ \\
\hline Other & $1.02(1.00,1.04)$ & $63.54(60.63,66.59)$ & .059 \\
\hline Commercial & Reference & $62.31(59.70,65.03)$ & \\
\hline \multicolumn{4}{|c|}{ Median Household Income Quartile } \\
\hline Q1 & $1.02(1.01,1.03)$ & $64.14(61.43,66.98)$ & $<.001$ \\
\hline \multicolumn{4}{|c|}{ Any Technology Dependence } \\
\hline Yes & $0.97(0.96,0.98)$ & $62.66(59.98,65.47)$ & $<.001$ \\
\hline No & Reference & $64.46(61.75,67.29)$ & \\
\hline \multicolumn{4}{|c|}{ Number of Chronic Conditions } \\
\hline 0 & Reference & $46.81(44.82,48.88)$ & \\
\hline 1 & $1.16(1.15,1.17)$ & $54.29(51.99,56.70)$ & $<.001$ \\
\hline 2 & $1.36(1.35,1.37)$ & $63.51(60.81,66.33)$ & $<.001$ \\
\hline 3 & $1.49(1.47,1.51)$ & $69.71(66.72,72.84)$ & $<.001$ \\
\hline 4 & $1.58(1.56,1.60)$ & $73.83(70.62,77.18)$ & $<.001$ \\
\hline $5+$ & $1.69(1.67,1.72)$ & $79.32(75.91,82.89)$ & $<.001$ \\
\hline \multicolumn{4}{|l|}{ Admitted through ED } \\
\hline Yes & $1.21(1.20,1.21)$ & $69.82(66.88,72.89)$ & $<.001$ \\
\hline No & Reference & $57.85(55.41,60.41)$ & \\
\hline \multicolumn{4}{|l|}{ ICU Stay } \\
\hline Yes & $1.67(1.65,1.68)$ & $82.06(78.56,85.72)$ & $<.001$ \\
\hline No & Reference & $49.22(47.15,51.38)$ & \\
\hline
\end{tabular}

Abbreviations: CCC; complex chronic conditions; $\mathrm{Cl}$, confidence interval; ED, emergency department; ICU, intensive care unit; LOS, length of stay. 
TABLE 2. Association between Patient Demographic and Clinical Characteristics and Readmissions.

\begin{tabular}{|c|c|c|c|}
\hline & $\begin{array}{l}\text { Odds Ratio } \\
\text { (95\% Cl) }\end{array}$ & $\begin{array}{l}\text { Adjusted Probability of Readmission } \\
\qquad(95 \% \mathrm{Cl})\end{array}$ & $P$ Value \\
\hline \multicolumn{4}{|l|}{ Day of Discharge } \\
\hline Weekday & Reference & $0.11(0.11,0.12)$ & \\
\hline \multicolumn{4}{|l|}{ Age Group } \\
\hline $0-30$ days & $1.21(1.13,1.30)$ & $0.14(0.12,0.15)$ & $<.001$ \\
\hline $1-4$ years & $0.97(0.93,1.02)$ & $0.11(0.11,0.12)$ & .223 \\
\hline $5-9$ years & $0.85(0.81,0.89)$ & $0.10(0.09,0.11)$ & $<.001$ \\
\hline $10-14$ years & $0.97(0.93,1.02)$ & $0.11(0.10,0.12)$ & $<.001$ \\
\hline $15-17$ years & Reference & $0.12(0.12,0.13)$ & \\
\hline \multicolumn{4}{|l|}{ Gender } \\
\hline Female & $1.01(0.98,1.03)$ & $0.12(0.11,0.13)$ & .485 \\
\hline Non-Hispanic Black & $0.94(0.90,0.97)$ & $0.11(0.11,0.12)$ & .831 \\
\hline Hispanic & $1.00(0.96,1.03)$ & $0.12(0.11,0.13)$ & .031 \\
\hline Asian & $1.09(1.01,1.17)$ & $0.13(0.12,0.14)$ & .164 \\
\hline Native American & $1.18(0.93,1.50)$ & $0.14(0.11,0.17)$ & $<.001$ \\
\hline Other & $0.88(0.84,0.93)$ & $0.11(0.10,0.11)$ & \\
\hline \multicolumn{4}{|l|}{ Payer } \\
\hline Government & $1.04(1.01,1.07)$ & $0.11(0.11,0.12)$ & .010 \\
\hline Commercial & Reference & $0.11(0.10,0.12)$ & \\
\hline Other & $1.25(1.14,1.37)$ & $0.13(0.12,0.15)$ & $<.001$ \\
\hline \multicolumn{4}{|c|}{ Median Household Income Quartile } \\
\hline Q1 & $0.95(0.91,0.98)$ & $0.12(0.11,0.12)$ & .005 \\
\hline \multicolumn{4}{|c|}{ Any Technology Dependence } \\
\hline Yes & $1.15(1.11,1.20)$ & $0.13(0.12,0.14)$ & $<.001$ \\
\hline No & Reference & $0.11(0.11,0.12)$ & \\
\hline \multicolumn{4}{|c|}{ Number of Chronic Conditions } \\
\hline 0 & Reference & & \\
\hline 1 & $1.71(1.65,1.78)$ & $0.05(0.04,0.05)$ & $<.001$ \\
\hline 2 & $2.70(2.58,2.82)$ & $0.08(0.07,0.08)$ & $<.001$ \\
\hline 3 & $3.64(3.46,3.83)$ & $0.12(0.11,0.13)$ & $<.001$ \\
\hline 4 & $4.38(4.13,4.64)$ & $0.15(0.14,0.16)$ & $<.001$ \\
\hline $5+$ & $5.93(5.62,6.27)$ & $0.18(0.17,0.19)$ & $<.001$ \\
\hline \multicolumn{4}{|l|}{ Admitted through ED } \\
\hline Yes & $0.93(0.91,0.96)$ & $0.12(0.11,0.12)$ & $<.001$ \\
\hline No & Reference & $0.12(0.12,0.13)$ & \\
\hline \multicolumn{4}{|l|}{ ICU Stay } \\
\hline Yes & $0.95(0.91,0.99)$ & $0.12(0.11,0.13)$ & .017 \\
\hline No & Reference & $0.12(0.12,0.13)$ & \\
\hline
\end{tabular}

Abbreviations: CCC; complex chronic conditions; Cl, confidence interval; ED, emergency department; ICU, intensive care unit. 
2.0

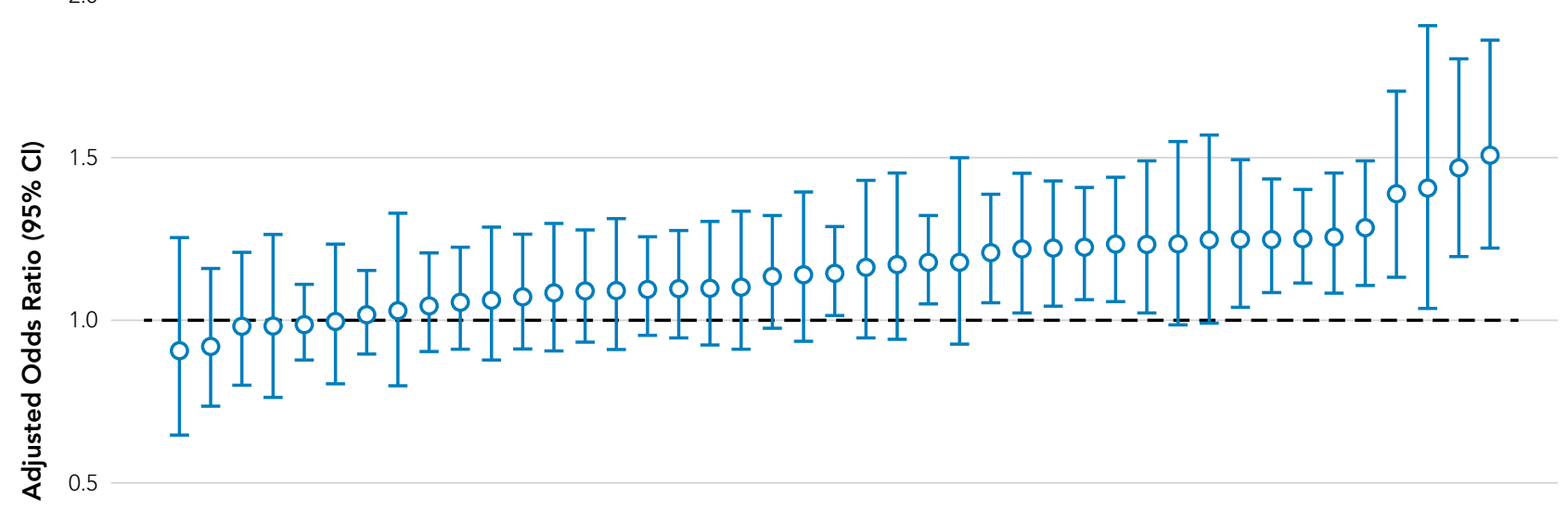

0.0

\section{PHIS Hospital}

FIG 2. Comparison of adjusted odds of readmission for weekend versus weekday discharges across 43 Pediatric Health Information System (PHIS) hospitals. Data are presented as adjusted odds ratios with $95 \% \mathrm{Cl}$. Values $>1.0$ are observed for hospitals where weekend discharges were associated with higher readmission rates, while values $<1.0$ are observed for hospitals where weekend discharges were associated with lower readmission rates.

was associated with increased probability of readmission compared with weekday discharge (adjusted probability of readmission [95\% Cl]: weekend 0.13 [0.12-0.13] vs weekday 0.11 [0.11-0.12], $P<.001)$.

\section{DISCUSSION}

In this multicenter retrospective study, we observed substantial variation across hospitals in the relationship between weekend admission and LOS and weekend discharge and readmission rates. Overall, we did not observe an association between weekend admission and LOS. However, significant associations were noted between weekend admission and LOS at some hospitals, although the magnitude and direction of the effect varied. We observed a modestly increased risk of readmission among those discharged on the weekend. At the hospital level, the association between weekend discharge and increased readmissions was statistically significant at $39.5 \%$ of hospitals. Not surprisingly, certain patient demographic and clinical characteristics, including medical complexity and number of chronic conditions, were also associated with LOS and readmission risk. Taken together, our findings demonstrate that among a large sample of children, the degree to which a weekend admission or discharge impacts LOS or readmission risk varies considerably according to specific patient characteristics and individual hospital.

While the reasons for the weekend effect are unclear, data supporting this difference have been observed across many diverse patient groups and health systems both nationally and internationally. ${ }^{13-27,31}$ Weekend care is thought to differ from weekday care because of differences in physician and nurse staffing, availability of ancillary services, access to diagnostic testing and therapeutic interventions, ability to arrange outpatient follow-up, and individual patient clinical factors, including acuity of illness. Few studies have assessed the effect of weekend discharges on patient or system outcomes. Among children within a single health system, readmission risk was associated with weekend admission but not with weekend discharge. ${ }^{22}$ This observation suggests that if differential care exists, then it occurs during initial clinical management rather than during discharge planning. Consequently, understanding the interaction of weekend admission and LOS is important. In addition, the relative paucity of pediatric data examining a weekend discharge effect limits the ability to generalize these findings across other hospitals or health systems.

In contrast to prior work, we observed a modest increased risk for readmission among those discharged on the weekend in a large sample of children. Auger and Davis reported a lack of association between weekend discharge and readmissions at one tertiary care children's hospital, citing reduced discharge volumes on the weekend, especially among children with medical complexity, as a possible driver for their observation. ${ }^{22}$ The inclusion of a much larger population across 43 hospitals in our study may explain our different findings compared with previous research. In addition, the inclusion/exclusion criteria differed between the two studies; we excluded index admissions for planned procedures in this study (which are more likely to occur during the week), which may have contributed to the differing conclusions. Although Auger and Davis suggest that differences in initial clinical management may be responsible for the weekend effect, ${ }^{22}$ our observations suggest that discharge planning practices may also contribute to readmission risk. For example, a family's inability to access 
compounded medications at a local pharmacy or to access primary care following discharge could reasonably contribute to treatment failure and increased readmission risk. Attention to improving and standardizing discharge practices may alleviate differences in readmission risk among children discharged on a weekend.

Individual patient characteristics greatly influence LOS and readmission risk. Congruent with prior studies, medical complexity and technology dependence were among the factors in our study that had the strongest association with LOS and readmission risk. ${ }^{32}$ As with prior studies ${ }^{22}$, we observed that children with medical complexity and technology dependence were less frequently admitted and discharged on a weekend than on a weekday, which suggests that physicians may avoid complicated discharges on the weekend. Children with medical complexity present a unique challenge to physicians when assessing discharge readiness, given that these children frequently require careful coordination of durable medical equipment, obtainment of special medication preparations, and possibly the resumption or establishment of home health services. Notably, we cannot discern from our data what proportion of discharges may be delayed over the weekend secondary to challenges involved in coordinating care for children with medical complexity. Future investigations aimed at assessing physician decision making and discharge readiness in relation to discharge timing among children with medical complexity may establish this relationship more clearly.

We observed substantial variation in LOS and readmission risk across 43 tertiary care children's hospitals. Since the 1970s, numerous studies have reported worse outcomes among patients admitted on the weekend. While the majority of studies support the weekend effect, several recent studies suggest that patients admitted on the weekend are at no greater risk of adverse outcomes than those admitted during the week. ${ }^{35-}$ 37 Our work builds on the existing literature, demonstrating a complex and variable relationship between weekend admission/discharge, LOS, and readmission risk across hospitals. Notably, while many hospitals in our study experienced a significant weekend effect in LOS or readmission risk, only four hospitals experienced a statistically significant weekend effect for both LOS and readmission risk (three hospitals experienced increased risk for both, while one hospital experienced increased readmission risk but decreased LOS). Future investigations of the weekend effect should focus on exploring the differences in admission/discharge practices and staffing patterns of hospitals that did or did not experience a weekend effect.

This study has several limitations. We may have underestimated the total number of readmissions because we are unable to capture readmissions to other institutions by using the PHIS database. Our definition of a weekend admission or discharge did not account for three-day weekends or other holidays where staffing issues would be expected to be similar to that on weekends; consequently, our approach would be expected to bias the results toward null. Thus, a possible (but unlikely) result is that our approach masked a weekend effect that might have been more prominent had holidays been included. Although prior studies suggest that low physician/nurse staffing volumes and high patient workload are associated with worse patient outcomes, ${ }^{38,39}$ we are unable to discern the role of differential staffing patterns, patient workload, or service availability in our observations using the PHIS database. Moreover, the PHIS database does not allow for any assessment of the preventability of a readmission or the impact of patient/family preference on the decision to admit or discharge, factors that could reasonably contribute to some of the observed variation. Finally, the PHIS database contains administrative data only, thus limiting our ability to fully adjust for patient severity of illness and sociodemographic factors that may have affected clinical decision making, including discharge decision making.

\section{CONCLUSION}

In a study of 43 children's hospitals, children discharged on the weekend had a slightly increased readmission risk compared with children discharged on a weekday. Wide variation in the weekend effect on LOS and readmission risk was evident across hospitals. Individual patient characteristics had a greater impact on LOS and readmission risk than the weekend effect. Future investigations aimed at understanding which factors contribute most strongly to a weekend effect within individual hospitals (eg, differences in institutional admission/ discharge practices) may help alleviate the weekend effect and improve healthcare quality.

\section{Acknowledgments}

This manuscript resulted from "Paper in a Day," a Pediatric Research in Inpatient Settings (PRIS) Network-sponsored workshop presented at the Pediatric Hospital Medicine 2017 annual meeting. Workshop participants learned how to ask and answer a health services research question and efficiently prepare a manuscript for publication. The following are the members of the PRIS Network who contributed to this work: Jessica L. Bettenhausen, MD; Rebecca M. Cantu, MD, MPH; Jillian M Cotter, MD; Megan Deisz, MD; Teresa Frazer, MD; Pratichi Goenka, MD; Ashley Jenkins, MD; Kathryn E. Kyler, MD; Janet T. Lau, MD; Brian E. Lee, MD; Christiane Lenzen, MD; Trisha Marshall, MD; John M. Morrison MD, PhD; Lauren Nassetta, MD; Raymond Parlar-Chun, MD; Sonya Tang Girdwood MD, PhD; Tony R Tarchichi, MD; Irina G. Trifonova, MD; Jacqueline M. Walker, MD, MHPE; and Susan C. Walley, MD. See appendix for contact information for members of the PRIS Network.

Disclosures: The authors have no conflicts of interest to disclose.

Funding: The authors have no financial relationships relevant to this article to disclose.

\section{References}

1. Crossing the Quality Chasm: The IOM Health Care Quality Initiative : Health and Medicine Division. http://www.nationalacademies.org/hmd/Global/ News\%20Announcements/Crossing-the-Quality-Chasm-The-IOM-HealthCare-Quality-Initiative.aspx. Accessed November 20, 2017.

2. Institute for Healthcare Improvement: IHI Home Page. http://www.ihi.org:80/ Pages/default.aspx. Accessed November 20, 2017.

3. Berry JG, Zaslavsky AM, Toomey SL, et al. Recognizing differences in hospital quality performance for pediatric inpatient care. Pediatrics. 2015;136(2):251262. doi:10.1542/peds.2014-3131

4. NQF: All-Cause Admissions and Readmissions Measures - Final Report. http:// www.qualityforum.org/Publications/2015/04/All-Cause_Admissions_and_Readmissions_Measures___Final_Report.aspx. Accessed March 24, 2018. 
5. Hospital Inpatient Potentially Preventable Readmissions Information and Reports. https://www.illinois.gov/hfs/MedicalProviders/hospitals/PPRReports/ Pages/default.aspx. Accessed November 6, 2016.

6. Potentially Preventable Readmissions in Texas Medicaid and CHIP Programs - Fiscal Year 2013 | Texas Health and Human Services. https://hhs.texas. gov/reports/2016/08/potentially-preventable-readmissions-texas-medicaid-and-chip-programs-fiscal-year. Accessed November 6, 2016

7. Statewide Planning and Research Cooperative System. http://www.health ny.gov/statistics/sparcs/sb/. Accessed November 6, 2016.

8. HCA Implements Potentially Preventable Readmission (PPR) Adjustments. Wash State Hosp Assoc. http://www.wsha.org/articles/hca-implements-potentially-preventable-readmission-ppr-adjustments/. Accessed November 8, 2016

9. Berry JG, Toomey SL, Zaslavsky AM, et al. Pediatric readmission prevalence and variability across hospitals. JAMA. 2013;309(4):372-380. doi:10.1001/ jama.2012.188351

10. Bardach NS, Vittinghoff E, Asteria-Peñaloza R, et al. Measuring hospital quality using pediatric readmission and revisit rates. Pediatrics. 2013;132(3):429 436. doi:10.1542/peds.2012-3527

11. Berry JG, Blaine K, Rogers J, et al. A framework of pediatric hospital discharge care informed by legislation, research, and practice. JAMA Pediatr. 2014;168(10):955-962; quiz 965-966. doi:10.1001/jamapediatrics.2014.891

12. Auger KA, Simon TD, Cooperberg D, et al. Summary of STARNet: seamless transitions and (Re)admissions network. Pediatrics. 2015;135(1):164 doi:10.1542/peds.2014-1887

13. Freemantle N, Ray D, McNulty D, et al. Increased mortality associated with weekend hospital admission: a case for expanded seven day services? BMJ. 2015;351:h4596. doi:10.1136/bmj.h4596

14. Schilling PL, Campbell DA, Englesbe MJ, Davis MM. A comparison of in-hospital mortality risk conferred by high hospital occupancy, differences in nurse staffing levels, weekend admission, and seasonal influenza. Med Care. 2010;48(3):224-232. doi:10.1097/MLR.0b013e3181c162c0

15. Cram P, Hillis SL, Barnett M, Rosenthal GE. Effects of weekend admission and hospital teaching status on in-hospital mortality. Am J Med. 2004;117(3):151 157. doi:10.1016/j.amjmed.2004.02.035

16. Zapf MAC, Kothari AN, Markossian T, et al. The "weekend effect" in urgent general operative procedures. Surgery. 2015;158(2):508-514. doi:10.1016/j. surg.2015.02.024

17. Freemantle N, Richardson M, Wood J, et al. Weekend hospitalization and additional risk of death: an analysis of inpatient data. J R Soc Med. 2012;105(2):74-84. doi:10.1258/jrsm.2012.120009

18. Bell CM, Redelmeier DA. Mortality among patients admitted to hospitals on weekends as compared with weekdays. N Engl J Med. 2001;345(9):663-668. doi:10.1056/NEJMsa003376

19. Coiera E, Wang Y, Magrabi F, Concha OP, Gallego B, Runciman W. Predicting the cumulative risk of death during hospitalization by modeling weekend, weekday and diurnal mortality risks. BMC Health Serv Res. 2014;14:226. doi:10.1186/1472-6963-14-226

20. Powell ES, Khare RK, Courtney DM, Feinglass J. The weekend effect for patients with sepsis presenting to the emergency department. J Emerg Med. 2013;45(5):641-648. doi:10.1016/j.jemermed.2013.04.042

21. Ananthakrishnan AN, McGinley EL, Saeian K. Outcomes of weekend admissions for upper gastrointestinal hemorrhage: a nationwide analysis. Clin Gas troenterol Hepatol Off Clin Pract J Am Gastroenterol Assoc. 2009;7(3):296 302e1. doi:10.1016/j.cgh.2008.08.013

22. Auger KA, Davis MM. Pediatric weekend admission and increased unplanned readmission rates. J Hosp Med. 2015;10(11):743-745. doi:10.1002/jhm.2426
23. Goldstein SD, Papandria DJ, Aboagye J, et al. The "weekend effect" in pediatric surgery - increased mortality for children undergoing urgent surgery during the weekend. J Pediatr Surg. 2014;49(7):1087-1091. doi:10.1016/j. jpedsurg.2014.01.001

24. Adil MM, Vidal G, Beslow LA. Weekend effect in children with stroke in the nationwide inpatient sample. Stroke. 2016;47(6):1436-1443. doi:10.1161/ STROKEAHA. 116.013453

25. McCrory MC, Spaeder MC, Gower EW, et al. Time of admission to the PICU and mortality. Pediatr Crit Care Med J Soc Crit Care Med World Fed Pediatr Intensive Crit Care Soc. 2017;18(10):915-923. doi:10.1097/ PCC.0000000000001268

26. Mangold WD. Neonatal mortality by the day of the week in the 1974-75 Arkansas live birth cohort. Am J Public Health. 1981;71(6):601-605.

27. MacFarlane A. Variations in number of births and perinatal mortality by day of week in England and Wales. Br Med J. 1978;2(6153):1670-1673.

28. McShane P, Draper ES, McKinney PA, McFadzean J, Parslow RC, Paediatric intensive care audit network (PICANet). Effects of out-of-hours and winter admissions and number of patients per unit on mortality in pediatric intensive care. J Pediatr. 2013;163(4):1039-1044.e5. doi:10.1016/j.jpeds.2013.03.061

29. Hixson ED, Davis S, Morris S, Harrison AM. Do weekends or evenings matter in a pediatric intensive care unit? Pediatr Crit Care Med J Soc Crit Care Med World Fed Pediatr Intensive Crit Care Soc. 2005;6(5):523-530.

30. Gonzalez KW, Dalton BGA, Weaver KL, Sherman AK, St Peter SD, Snyder CL. Effect of timing of cannulation on outcome for pediatric extracorporeal life support. Pediatr Surg Int. 2016;32(7):665-669. doi:10.1007/s00383-016-3901-6

31. Desai V, Gonda D, Ryan SL, et al. The effect of weekend and after-hours surgery on morbidity and mortality rates in pediatric neurosurgery patients. J Neurosurg Pediatr. 2015;16(6):726-731. doi:10.3171/2015.6.PEDS15184

32. Berry JG, Hall DE, Kuo DZ, et al. Hospital utilization and characteristics of patients experiencing recurrent readmissions within children's hospitals. JAMA. 2011;305(7):682-690. doi:10.1001/jama.2011.122

33. Hoshijima $H$, Takeuchi $R$, Mihara $T$, et al. Weekend versus weekday admission and short-term mortality: A meta-analysis of 88 cohort studies including 56,934,649 participants. Medicine (Baltimore). 2017;96(17):e6685. doi:10.1097/MD.0000000000006685

34. Feudtner C, Feinstein JA, Zhong W, Hall M, Dai D. Pediatric complex chronic conditions classification system version 2: updated for ICD-10 and complex medical technology dependence and transplantation. BMC Pediatr. 2014;14:199. doi:10.1186/1471-2431-14-199

35. Li L, Rothwell PM, Oxford Vascular Study. Biases in detection of apparent "weekend effect" on outcome with administrative coding data: population based study of stroke. BMJ. 2016;353:i2648. doi: 10.1136/bmj.i2648

36. Bray BD, Cloud GC, James MA, et al. Weekly variation in health-care quality by day and time of admission: a nationwide, registry-based, prospective cohort study of acute stroke care. The Lancet. 2016;388(10040):170-177. doi:10.1016/S0140-6736(16)30443-3

37. Ko SQ, Strom JB, Shen C, Yeh RW. Mortality, Length of Stay, and Cost of Weekend Admissions. J Hosp Med. 2018. doi:10.12788/jhm.2906

38. Tubbs-Cooley HL, Cimiotti JP, Silber JH, Sloane DM, Aiken LH. An observational study of nurse staffing ratios and hospital readmission among children admitted for common conditions. BMJ Qual Saf. 2013;22(9):735-742. doi:10.1136/bmjgs-2012-001610

39. Ong M, Bostrom A, Vidyarthi A, McCulloch C, Auerbach A. House staff team workload and organization effects on patient outcomes in an academic general internal medicine inpatient service. Arch Intern Med. 2007:167(1):47-52. doi:10.1001/archinte.167.1.47 